\title{
Diagnosis and Assessment of Metallurgical Industry Wastewater Treatment Technology of Liaohe Basin
}

\author{
YongYong Wang ${ }^{1, a}$, Xiang $\mathrm{He}^{1}$, Runlei Cai ${ }^{1}$, Fan Wang ${ }^{1}$ \\ ${ }^{1}$ School of Municipal and Environmental Engineering, Shenyang Jianzhu University, Shenyang, \\ 110168, China \\ aemail: yingwang_1986@126.com
}

\section{Keywords: Metallurgical Industry, Technology Assessment, Model}

\begin{abstract}
For liaohe basin metallurgical industry wastewater treatment technology lack of optimization, selection of technical parameters of the lack of rationality ,management of large scale and lack of in the near and specified future date unified combination, existing metallurgical wastewater treatment technology after a certain time after the operation the current situation of the operation and management or technical problems; In this paper, by constructing liaohe basin metallurgical waste water treatment technology evaluation system evaluation model, find out by the problems existing in the assessment of metallurgical wastewater treatment technology, put forward the corresponding improvement Suggestions, for metallurgical enterprises provide a scientific basis for choose new wastewater treatment technology, improve the metallurgical treatment effect of wastewater treatment technology.
\end{abstract}

\section{Introduction}

According to the liaoning province environmental statistics, liaohe basin, the existing more than 700 in metallurgical enterprises, including ferrous metallurgy and non-ferrous metallurgy, selecting, sintering, steel rolling, ironmaking and steelmaking production, the main pollutants of the metallurgical waste water COD, SS, and oils, greater damage to the environment.According to statistics, liaohe basin metallurgical waste water treatment technology penetration rate is only $60 \%$, low penetration metallurgical wastewater treatment technology is a big barrier of liaohe basin metallurgical waste water treatment, waste water treatment and liaohe river metallurgy technology by simple physical and chemical method, treatment effect is poor, low automation control, add most of the agents, and other conditions control to manual control, metallurgical wastewater treatment effect is not technology guarantee.

\section{The Construction of Evaluation Model}

Evaluation model is an important part of wastewater treatment technology assessment, evaluation model by the evaluation index system, weight determination method, comprehensive evaluation method, the validation method, the sensitivity analysis method.Build suitable for liaohe basin evaluation model of metallurgical wastewater treatment technology, not only of liaohe basin in metallurgy and metallurgical wastewater treatment technology has a deep understanding of, and familiar with the advantages and disadvantages of assessment method and to evaluate the applicability of the liaohe basin metallurgical waste water treatment technology.According to the characteristics of the wastewater of metallurgy, liaohe basin specific environmental characteristics to establish evaluation index system, through the field investigation, data access, expert scoring methods such as the raw data of each index, then using chromatography analysis and principal component analysis (PCA) to determine the weight of each index. With the index weight, on the basis of using the cloud barycenter judgement method to evaluate governance technology is evaluated, the evaluation results are obtained.On the basis of the results of the assessment, sensitivity analysis was carried out on the bioremediation technology, find out the disadvantages of management technology in theory, according to the results of sensitivity analysis to improve the management technology, make its can be better used in liaohe basin metallurgical waste water 
treatment, assessment model implementation process is shown in figure 1:

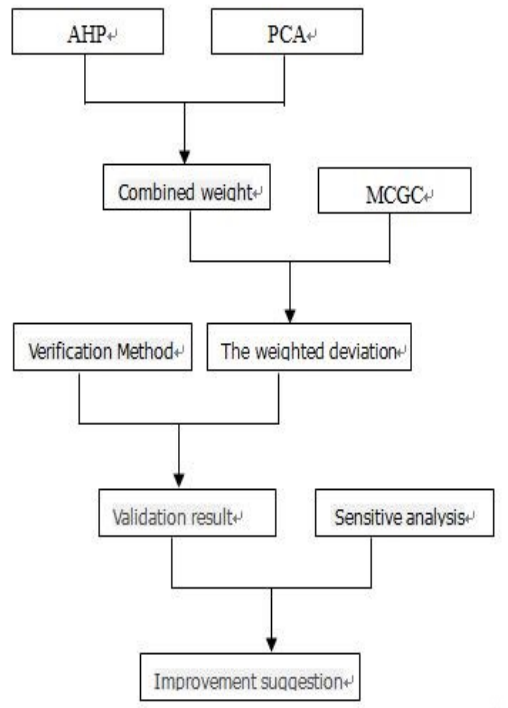

Fig1 Assessment Flowchart

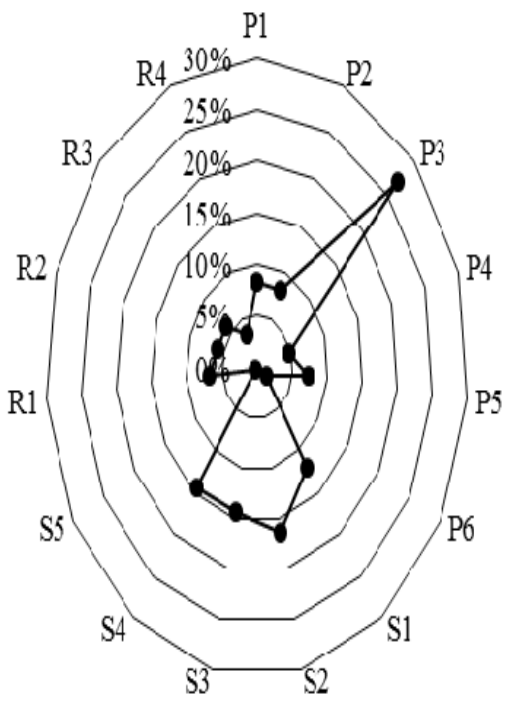

Fig 2 Sensitivity analysis technique of A

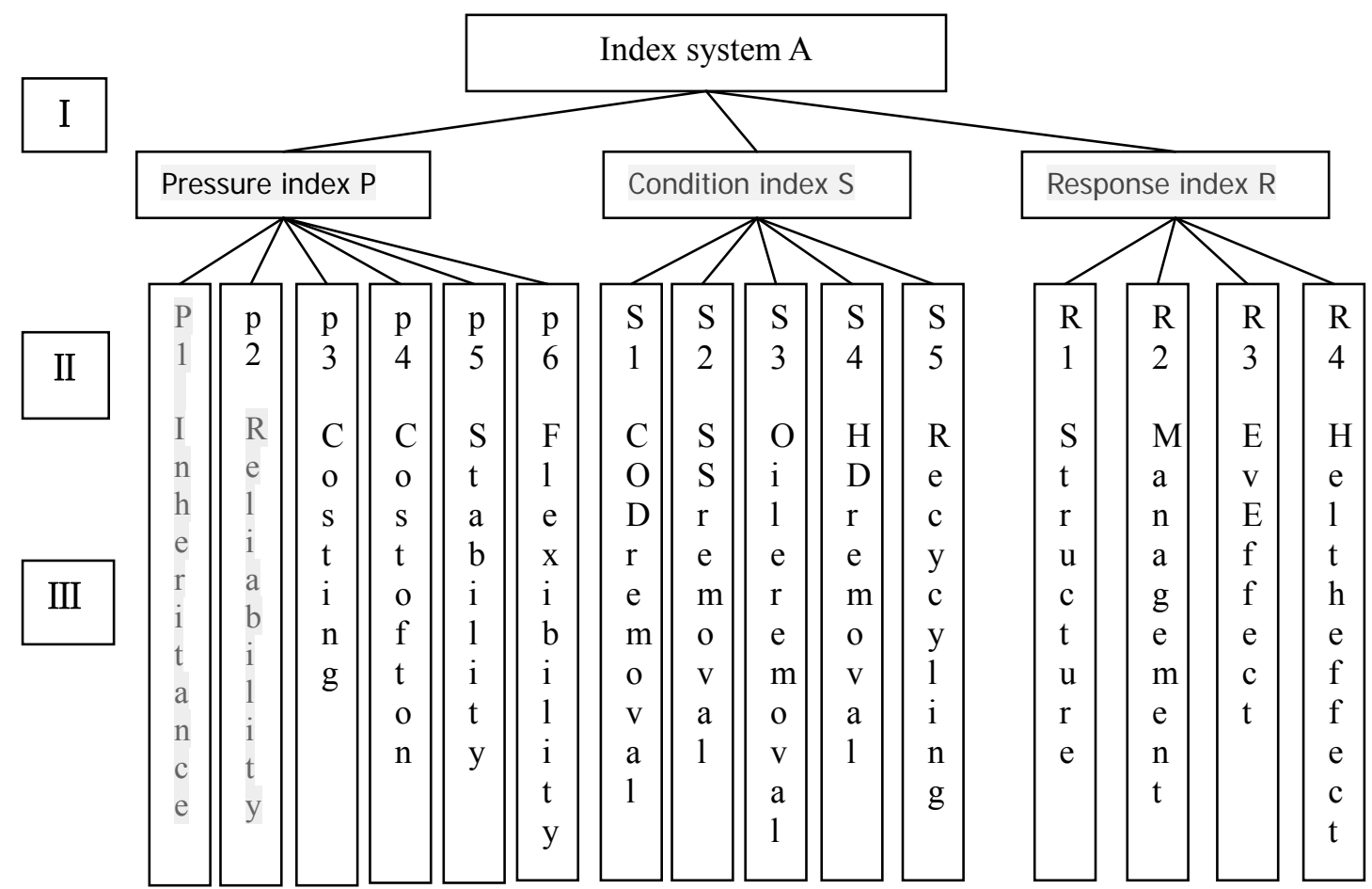

Fig3 Metallurgical waste water treatment technology evaluation index system

\section{The Index Weight Determination}

Using analytic hierarchy process (AHP) and principal component analysis (PCA) to subjective and objective integrated to determine index weight, analytic hierarchy process (AHP) is a kind of lay particular stress on the subjective weight determination method, principal component analysis (PCA) is a kind of lay particular stress on the objective weight determination method, two methods can be avoided by combination weighting results are too subjective, and can avoid weight results away from the actual situation.Adopts the fuzzy index processing more scientific evaluation method of cloud CG comprehensive assessment of metallurgical wastewater treatment technology is shown in figure 2. 


\section{Typical Metallurgical Wastewater Treatment Technology Assessment}

This research adopts 5 kinds of liaohe river basin integrated iron and steel metallurgical wastewater commonly used to evaluate treatment technology as an actual case, five steel enterprises respectively named A factory and B factory, C, D and E factory; Corresponding technology respectively named $\mathrm{A}, \mathrm{B}, \mathrm{C}, \mathrm{D}$ and $\mathrm{E}$.The five technologies evaluation model of the input, output results shown in the following table 1 :

Table 1. The Technology of Correlation

\begin{tabular}{|c|c|c|c|c|c|}
\hline Technical Name & A & B & C & D & E \\
\hline Total Correlation & 0.872 & 0.741 & 0.779 & 0.611 & 0.787 \\
\hline
\end{tabular}

\section{Conclusion}

This research established evaluation model the optimal and worse order to get to the A, E, C, B, D.According to the features of metallurgical wastewater treatment technology assessment, the study of each index by $10 \%$ respectively fixed step length to disturbance of evaluation model, the change of various index range between $80 \%$ and $120 \%$ respectively, and the index of original value to $20 \%$, respectively, $10 \%, 10 \%$ and $20 \%$, other indicators of original value remains the same, sensitivity analysis was carried out on the model, with A technology as the example analysis results as shown in figure 2, the sensitivity analysis results conform to the actual engineering situation, the indexes to evaluate the results of sensitivity in order for P3S2S4S3S1P1P2P5R1R2R3P4R4P6S5 .It can be seen that the sensitivity factor for running cost P3, S2, removal rate of SS removal rate of hardness $\mathrm{S} 4, \mathrm{~S} 3$, removal rate of oil removal rate of COD S1, sensitivity is over $10 \%$.

\section{Acknowledgement}

In this paper, the research was sponsored by the China Environmental Protection Foundation of "123 Project"(Project No. CEPF2012-123-2-3) and Main Pollutant Emission Control and Management System Construction of Liao River Basin (Project No. 2012ZX07505-002-002).

\section{References}

[1]Fu Jinxiang,Xie Lingwei,Qu Ming.Entropy TOPSIS method in the application of the slaughtering industry wastewater treatment evaluation[J].Journal of Shenyang Jianzhu university,2012,28(5):909-914.

[2]Tang Ran,Long Tengrui,Long Xiangyu.Qiu Yulin.The fuzzy grey correlation method in wastewater treatment for the application of technology assessment[J].Water Supply and Drainage,2008,34:336-340.

[3]Xinping Xiao.About the quantitative model of grey correlation theory research and comments [J].Systems Engineering Theory and Practicel, 1997, 08:77-82.

[4]Palme U, Lundin M, Tillman A M, et al. Sustainable development indicators for wastewater systems-researchers and indicator users in a co-operative case study. Resource Conservation \& Recycling [J]. 2005(43):293-311.

[5] Molion M, Garrido M, Reif R, et al. Assessment of wastewater treatment plant design for small communities: Environmental and economic aspects [J]. Science of the Total Environment, 2012, 427- 428(15):11-18.

[6] Couillard D. A framework for technological choice ( a technology assessment: Methodology for the choice of wastewater treatment facilities) [J]. Journal of Environmental Systems, 1988, 18(1): 49- 67. 